
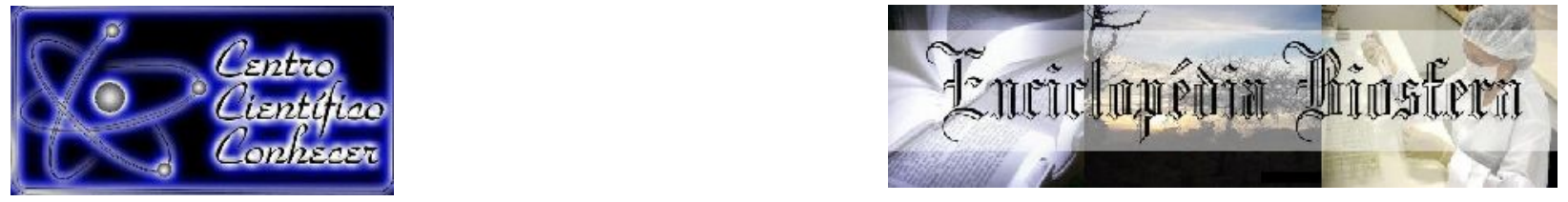

\title{
RELAÇÃO DA MASSA ESPECÍFICA E TEOR DE UMIDADE DA MADEIRA DE Maclura tinctoria AO LONGO DO FUSTE
}

\author{
Luana Candaten $^{1}$; Tauana Mangini ${ }^{1}$; Eduarda Bandera ${ }^{1}$; Rômulo Trevisan $^{2}$; Henrique \\ Weber Dalla Costa ${ }^{3}$ \\ ${ }^{1}$ Graduandas em Engenharia Florestal pela Universidade Federal de Santa Maria \\ Campus Frederico Westphalen \\ E-MAIL DE CONTATO; Luana_candaten@outlook.com \\ ${ }^{2}$ Professor Doutor do Departamento de Engenharia Florestal da Universidade \\ Federal de Santa Maria Campus Frederico Westphalen \\ ${ }^{3}$ Doutorando em Engenharia Florestal pela Universidade Federal de Santa Maria
}

\section{Recebido em: 22/09/2018 - Aprovado em: 23/11/2018 - Publicado em: 03/12/2018 DOI: 10.18677/EnciBio_2018B68}

\begin{abstract}
RESUMO
O uso da madeira proveniente de espécies nativas, as quais podem ter características tecnológicas desejáveis para diversos fins, tem crescido nos últimos tempos e, a partir do conhecimento das variações e correto manejo desse material, é possível o seu aproveitamento múltiplo de forma satisfatória. Assim, o presente trabalho teve como objetivo determinar a relação da massa específica e teor de umidade da madeira de Maclura tinctoria ao longo do fuste. Para a condução do estudo, após o abate de um indivíduo dessa espécie, foram confeccionados discos das posições da base, no diâmetro à 1,30 m do solo (DAP), 25, 50, 75 e 100\% da altura do primeiro galho vivo. Em seguida, foram seccionados em cunhas contendo a medula, com partes do cerne e alburno, para a caracterização das propriedades físicas da madeira a partir da norma ASTM D143-94 (1995). Os resultados evidenciaram que massa específica básica da madeira de Maclura tinctoria diminuiu com o aumento do teor de umidade e a massa específica aparente saturada apresentou uma tendência de acréscimo, porém sem diferença estatística. A massa específica básica e a aparente saturada foram menores em posições próximas ao topo da árvore, enquanto o teor de umidade se mostrou ligeiramente maior no sentido base-topo. De acordo com a massa específica básica ponderada em função do volume comercial sem casca, a madeira dessa espécie foi classificada como média.
\end{abstract}

PALAVRAS-CHAVE: espécie nativa; propriedades físicas; qualidade da madeira.

\section{RELATION BETWEEN SPECIFIC GRAVITY AND MOISTURE CONTENT OF Maclura tinctoria WOOD ALONG THE STEM}

\section{ABSTRACT}

The use of native species wood has grown in last times, in which they can have desirable technological features for various purposes, and, based on knowledge of material variations and its management, it is possible its multiple exploitation in satisfactory way. Thus, the present work aims to determine the relationship between ENCICLOPÉDIA BIOSFERA, Centro Científico Conhecer - Goiânia, v.15 n.28; p.845 
specific gravity and moisture content of Maclura tinctoria wood along the stem. In order to conduct the study, after an individual of this species was harvested, discs from base, in the diameter at $1.30 \mathrm{~m}$ height of soil (DBH), 25, 50, 75, and $100 \%$ height of first alive branch were made. Then, they were sectioned in wedges containing pith, heartwood, and sapwood, for wood physical properties characterization from ASTM D143-94 (1995) standard. The results evidences that Maclura tinctoria wood basic specific gravity decreases with increases of moisture content and the saturated apparent specific gravity shows an upward tendency, however without statistical difference. Both basic and apparent specific gravity were lower near to the treetop, while the moisture content in base-top direction was slightly larger. According to basic specific gravity weighted in function of commercial volume without bark, this specie wood was classified as average.

KEYWORDS: native species; physical properties; wood quality.

\section{INTRODUÇÃO}

De maneira geral, existem muitas vantagens na utilização de espécies nativas em relação às exóticas, porém a interação entre árvores de mesma classificação botânica pode variar de acordo com o local de crescimento (MATTOS et al., 2011). A partir dessa possibilidade, estudos avaliando as propriedades físicas com indivíduos provenientes de uma determinada região podem proporcionar melhor entendimento da sua variação, sendo fundamentais para a correta classificação e destinação final da matéria-prima (FUENTES-RAMÍREZ et al., 2011).

A partir disso, a análise criteriosa das características tecnológicas dessas espécies é importante, principalmente em função da escassa literatura existente a respeito, como, por exemplo, no caso da madeira de Maclura tinctoria IDENTIFICADOR BOTÂNICO, conhecida popularmente como amoreira-do-mato, pertence à família Moraceae (GALINDO et al., 2012) e com ocorrência desde a Amazônia até o Sul do Brasil (CARVALHO, 2003).

Dentre esses locais que uma mesma espécie pode se desenvolver, os estudos das propriedades físicas desses materiais podem apresentar resultados diversos em resposta as condições climáticas em que as árvores são expostas, as quais variam entre regiões (TRAUTENMÜLLER et al., 2014). Através dos parâmetros influenciados pela qualidade de sítio e demais componentes inerentes à madeira, a massa específica básica, obtida pela razão entre a massa seca e o volume verde do material (DIAS et al., 2017), possui relação com o rendimento das operações florestais e é uma excelente indicadora da qualidade da matéria-prima (BONDUELLE et al., 2015).

Outra propriedade que pode influenciar o material em suas especificidades é o teor de umidade, o qual é definido a partir da relação entre a quantidade de água existente na madeira no momento em que ocorre o abate do indivíduo e essa característica na condição anidra (CRISÓSTOMO et al., 2016). Esse parâmetro varia de diversas maneiras, como, por exemplo, entre árvores da mesma espécie, cerne e alburno na mesma árvore, discos amostrados em diferentes posições, estação do ano e, desse modo, de maneira geral, em madeiras com maior densidade, menor será o teor de umidade (SKAAR, 1988; LOPES ; GARCIA, 2002).

Em razão dos escassos estudos sobre as características tecnológicas da espécie, a avaliação das propriedades físicas da madeira torna-se fundamental para adequação aos mais diversos usos e para a difusão de informações úteis sobre o material. Portanto, o presente trabalho teve por objetivo determinar a relação da 
massa específica e teor de umidade da madeira de Maclura tinctoria ao longo do fuste.

\section{MATERIAL E MÉTODOS}

O material utilizado no presente estudo foi proveniente de uma árvore senil de Maclura tinctoria abatida na Universidade Federal de Santa Maria, campus de Frederico Westphalen. Para confecção das amostras, foram seccionados discos de, aproximadamente, $2 \mathrm{~cm}$ de espessura nas posições de 0,10 m (base), 25, 50, $75 \mathrm{e}$ $100 \%$ da altura comercial, e no diâmetro a 1,30 m do solo (DAP), os quais, após a identificação, foram embalados em sacos plásticos para minimizar a perda de umidade.

Em seguida, o material selecionado foi conduzido ao Laboratório de Tecnologia e Utilização de Produtos Florestais da UFSM/FW e foram submersos em água até a completa saturação das fibras. Posteriormente, dividiu-se o material em cunhas simetricamente opostas, contendo a medula e as porções de cerne e alburno.

A determinação da massa específica básica das amostras no sentido basetopo seguiu a norma ASTM D-143-94 (1995), ao passo que para obtenção do volume verde utilizou-se o método da balança hidrostática. Para a determinação do peso seco à $0 \%$ de umidade, os corpos de prova permaneceram em uma estufa com circulação de ar forçada a $103^{\circ} \mathrm{C}$ até peso constante. $\mathrm{O}$ cálculo da massa específica básica para as cunhas consistiu na razão entre o peso seco da madeira anidra e o volume saturado (Equação 1):

$$
\text { Me básica }=\frac{\mathrm{P} 0 \%}{\mathrm{VV}}
$$

Em que: Me básica $=$ massa específica básica $\left(\mathrm{g} / \mathrm{cm}^{3}\right) ; \mathrm{P} 0 \%=$ peso seco em estufa (g); e Vv = volume saturado $\left(\mathrm{cm}^{3}\right)$.

A massa específica aparente saturada foi determinada pela Equação 2:

$$
\text { Mea saturada }=\frac{P s}{V_{v}}
$$

Em que: Mea saturada $=$ massa específica aparente saturada $\left(\mathrm{g} / \mathrm{cm}^{3}\right) ; P s=$ peso saturado $(\mathrm{g})$; e $\mathrm{Vv}$ = volume saturado $\left(\mathrm{cm}^{3}\right)$.

Para obtenção da massa específica básica ou saturada ponderada, foram utilizadas as massas específicas do fuste, os volumes sem casca entre essas posições e o volume comercial sem casca da árvore (método de Smalian), conforme Equação 3: 


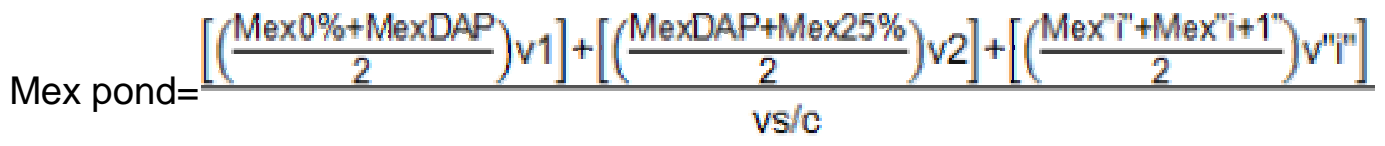

Em que: Mex pond = massa específica básica ou saturada ponderada em função do volume sem casca da árvore $\left(\mathrm{g} / \mathrm{cm}^{3}\right)$; Mex "i” = massa específica básica ou ponderada na posição "i" $\left(\mathrm{g} / \mathrm{cm}^{3}\right) ; \mathrm{v} 1, \mathrm{v} 2, \mathrm{v}$ "i" = volume sem casca correspondente a duas posições sucessivas $\left(\mathrm{cm}^{3}\right) ;$ e vs/c $=$ volume sem casca da árvore $\left(\mathrm{cm}^{3}\right)$. 4:

Para a determinação do teor de umidade das amostras foi utilizada a Equação

$$
\mathrm{TU}=\frac{\mathrm{Pu}-\mathrm{P} 0 \%}{\mathrm{P} 0 \%} \times 100
$$

Em que: $\mathrm{TU}=$ teor de umidade (\%); $\mathrm{Pu}=$ peso saturado $(\mathrm{g}) ;$ e $\mathrm{P} 0 \%=$ peso seco em estufa $(\mathrm{g})$.

Os dados de massa específica básica e aparente saturada foram relacionados com o teor de umidade e a posição relativa ao longo do fuste utilizando análise de regressão para delineamento experimental inteiramente casualizado com o auxílio do software estatístico Stratgraphics.

\section{RESULTADOS E DISCUSSÃO}

Os resultados obtidos para as propriedades físicas da madeira de Maclura tinctoria entre as diferentes posições ao longo do fuste apresentaram variação de 0,492 a $0,579 \mathrm{~g} / \mathrm{cm}^{3}$ para a massa específica básica, de 1,053 a $1,195 \mathrm{~g} / \mathrm{cm}^{3}$ para massa específica aparente saturada e uma amplitude de 100,6 a 130,1\% para o teor de umidade (Tabela 1).

TABELA 1 - Valores das propriedades físicas analisadas para a madeira de Maclura tinctoria.

\begin{tabular}{cccc}
\hline $\begin{array}{c}\text { Posição relativa } \\
\text { sentido base-topo } \\
\text { (\%) }\end{array}$ & $\begin{array}{c}\text { Massa específica } \\
\text { básica } \\
\left(\mathbf{g} / \mathbf{c m}^{3}\right)\end{array}$ & $\begin{array}{c}\text { Massa específica } \\
\text { aparente saturada } \\
\left(\mathbf{g} / \mathbf{c m}^{\mathbf{3}}\right)\end{array}$ & $\begin{array}{c}\text { Teor de } \\
\text { umidade } \\
\mathbf{( \% )}\end{array}$ \\
\hline Base $(0,10 \mathrm{~m})$ & 0,549 & 1,195 & 118,2 \\
DAP & $(0,042)$ & $(0,001)$ & $(16,8)$ \\
& 0,544 & 1,158 & 113,3 \\
25 & $(0,024)$ & $(0,036)$ & $(16,3)$ \\
& 0,570 & 1,161 & 103,8 \\
& $(0,009)$ & $(0,001)$ & $(3,4)$ \\
75 & 0,525 & 1,077 & 105,3 \\
& $(0,001)$ & $(0,034)$ & $(6,6)$ \\
100 & 0,500 & 1,122 & 124,6 \\
& $(0,034)$ & $(0,056)$ & $(4,4)$ \\
& 0,515 & 1,101 & 113,9 \\
\hline
\end{tabular}

Em que: DAP $=$ diâmetro a $1,30 \mathrm{~m}$ do solo. Valores entre parênteses representam 0 desvio padrão. 
A massa específica básica ponderada em função do volume comercial sem casca da árvore de Maclura tinctoria teve um resultado de $0,534 \mathrm{~g} / \mathrm{cm}^{3}$ que, de acordo com a classificação de Carvalho (1994), por estar entre os valores de 0,500 a $0,720 \mathrm{~g} / \mathrm{cm}^{3}$, enquadrou a madeira dessa espécie como média. Esse dado corroborou com o encontrado por Coldebella et al. (2018) para a mesma espécie, os quais evidenciaram essa propriedade com valor igual a $0,555 \mathrm{~g} / \mathrm{cm}^{3}$. Com relação a massa específica aparente saturada, o resultado ponderado em função do volume comercial sem casca de Maclura tinctoria obtido foi de $1,134 \mathrm{~g} / \mathrm{cm}^{3}$.

A relação entre a massa específica básica e o teor de umidade demonstrada na Figura 1 mostrou uma tendência de diminuição da quantidade de água à medida que ocorreu aumento de parede celular na madeira de Maclura tinctoria. Cabe ressaltar que a interação dessas propriedades apresentou a equação de regressão representada por "MEb $=0,769368$ - 0,002082*TU" com coeficiente de determinação ajustado ( $R^{2}$ aj.) igual a 0,44 , coeficiente de correlação de $-0,70$, valor de $F$ calculado de 9,83 e significativa ao nível de $5 \%$ de probabilidade de erro (Prob $>F=0,011$ ).

A redução na massa específica básica com o aumento do teor de umidade também foi observada por Juizo et al. (2015) e Friederichs et al. (2015), os valores mais acentuados de teor de umidade apresentaram os menores resultados de massa específica básica. Esse comportamento pode ser decorrente da relação peso e volume utilizados na obtenção da massa específica, pois, com o aumento do teor de umidade acima do ponto de saturação das fibras, somente a massa do material aumenta, não alterando o volume e resultando em menores valores dessa propriedade.

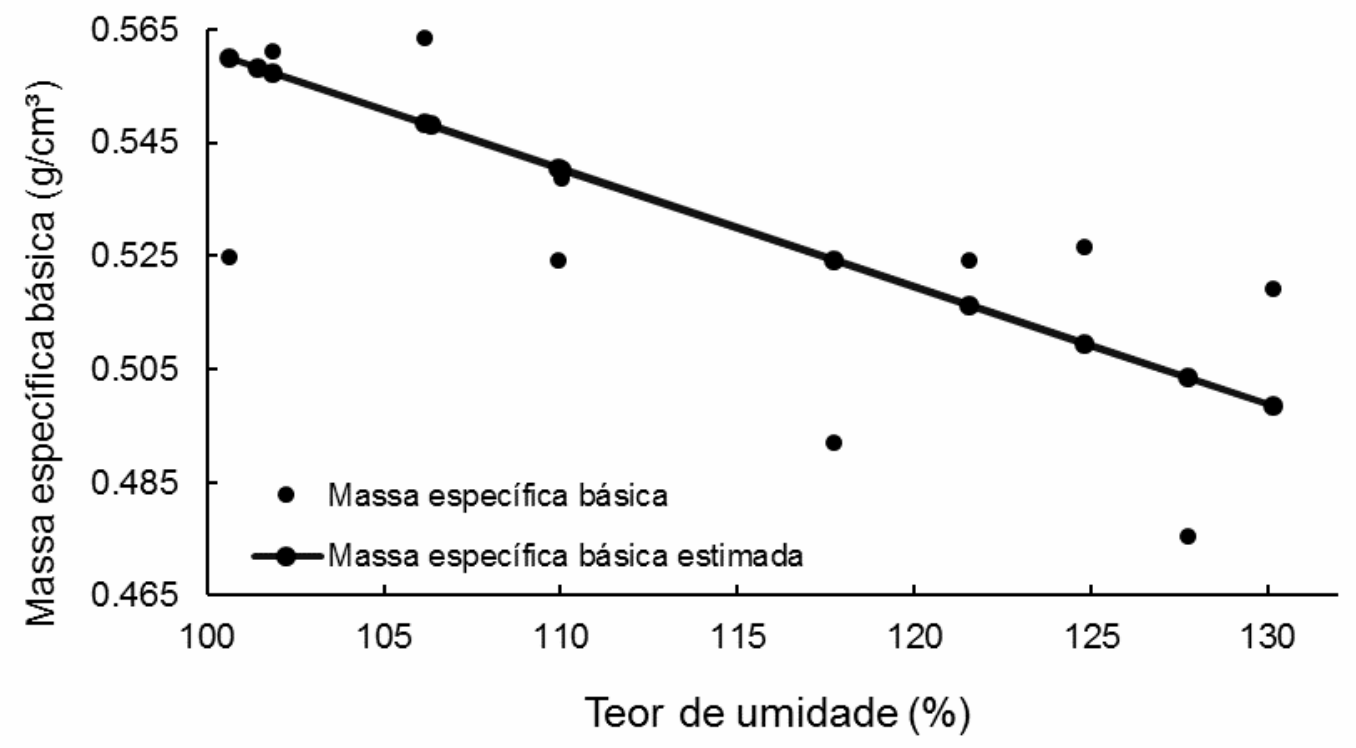

FIGURA 1 - Relação entre a massa específica básica com o teor de umidade para a madeira de Maclura tinctoria.

A interação da massa específica aparente saturada com o teor de umidade apresentou uma tendência de acréscimo a partir das análises nas mesmas condições citadas anteriormente, porém não demonstrou diferença de acordo com os parâmetros estatísticos avaliados.

A análise de regressão da massa específica básica em função da posição relativa no sentido base-topo mostrou um decréscimo com o aumento da altura 
comercial da árvore e ajustou o modelo "MEb $=0,556215$ - 0,000513*posição" (Figura 2). As estatísticas referentes a equação apresentaram coeficiente de determinação ajustado ( $R^{2}$ aj.) igual a 0,29 , coeficiente de correlação de $-0,59$, valor de $F$ calculado de 5,42 e significativo ao nível de $5 \%$ de probabilidade de erro (Prob $>F=0,042$ ). Por outro lado, o teor de umidade no sentido base-topo, apesar da tendência de acréscimo ao longo do fuste, não apresentou diferença estatística.

Para madeira da mesma espécie, Coldebella et al. (2018) observaram comportamento de massa específica básica semelhante ao obtido no presente estudo, sendo maior na base e diminuindo na direção do topo da árvore. Esse decréscimo ao longo do fuste também foi abordado por Pereira et al. (2013) e Beltrame et al. (2015), os quais discutiram que a presença de lenho juvenil é maior no topo da árvore e maiores concentrações de cerne se encontram na base, sendo condizente com a relação dos resultados de massa específica. Resultados semelhantes de redução da massa específica básica no sentido longitudinal também foram observados por Trautenmüller et al. (2014) estudando a espécie folhosa de Cordia americana Identificador botânico, com redução dessa propriedade ao longo do fuste.

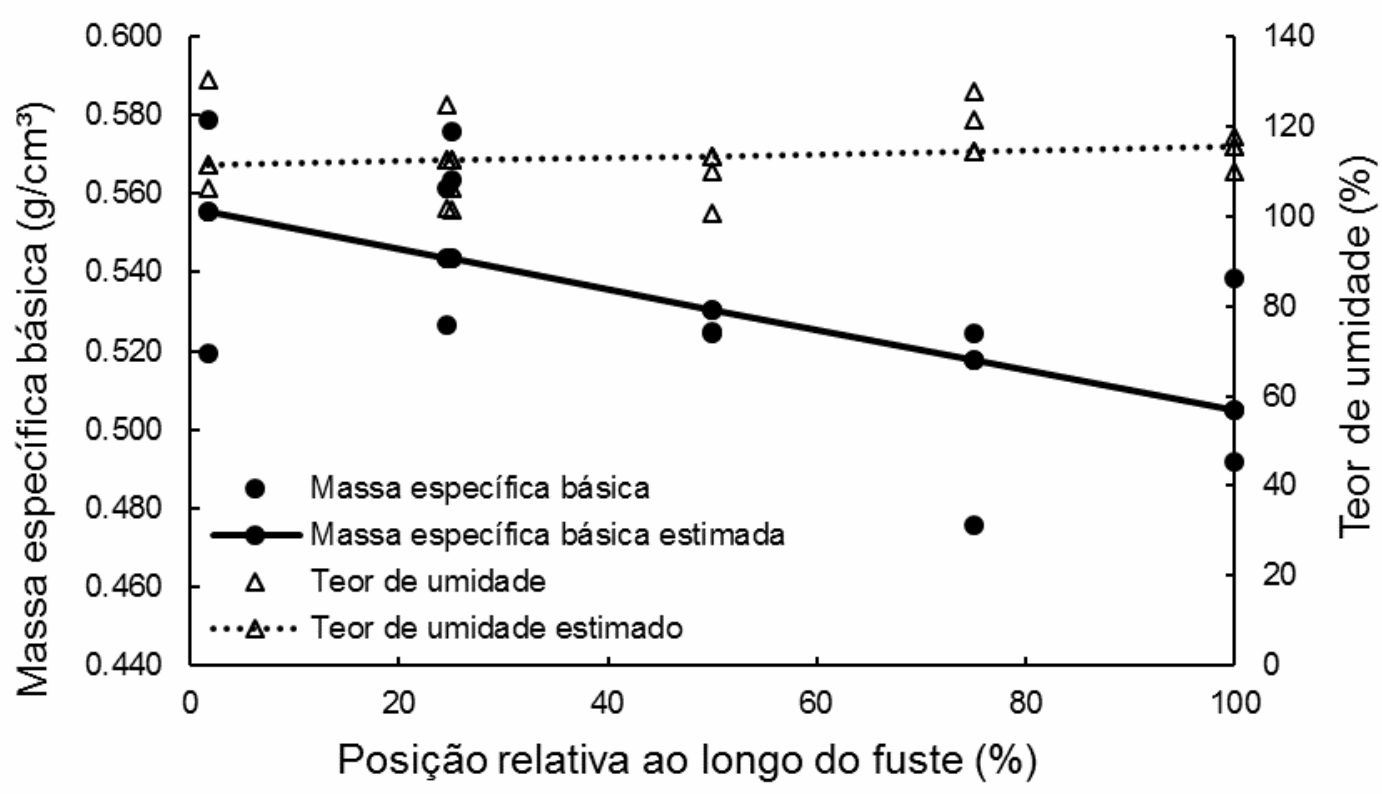

FIGURA 2 - Relação entre a massa específica básica e teor de umidade com a posição relativa ao longo do fuste da madeira de Maclura tinctoria.

A variação axial do teor de umidade apresentada na Figura 2 corroborou com o resultado de Oliveira et al. (2005) para diferentes espécies de eucalipto, cuja propriedade aumentou gradativamente da base para o topo, sendo maior próximo a altura total da árvore. Esse mesmo comportamento também foi observado por Cezaro et al. (2016) para a madeira de Chrysophyllum marginatum Identificador botânico, os quais discutiram que a relação do teor de umidade no sentido longitudinal foi inversamente proporcional a massa específica básica, concordando com os resultados apresentados na Figura 2.

A massa específica aparente saturada também diminuiu com o aumento da altura comercial do indivíduo (Figura 3), ou seja, mesma variação observada para a 
massa específica básica. A análise estatística a respeito da interação entre essas variáveis resultou na equação de regressão representada por "MEa $=1,174$ 0,000873*posição" com coeficiente de determinação ajustado ( $R^{2}$ aj.) igual a 0,37 , coeficiente de correlação de $-0,37$, valor de $F$ calculado de 7,52 e significativo ao nível de $5 \%$ de probabilidade de erro (Prob>F =0,021).

Relação semelhante da massa específica aparente, porém na condição seca a $12 \%$, foi observada no trabalho de Bonduelle et al. (2015) na madeira de Tectona grandis Identificador botânico, houve redução dessa propriedade no sentido longitudinal. Apesar da massa específica aparente no presente estudo ter sido estudada na condição saturada, a literatura aborda que, normalmente, ambas devem seguir a mesma tendência.

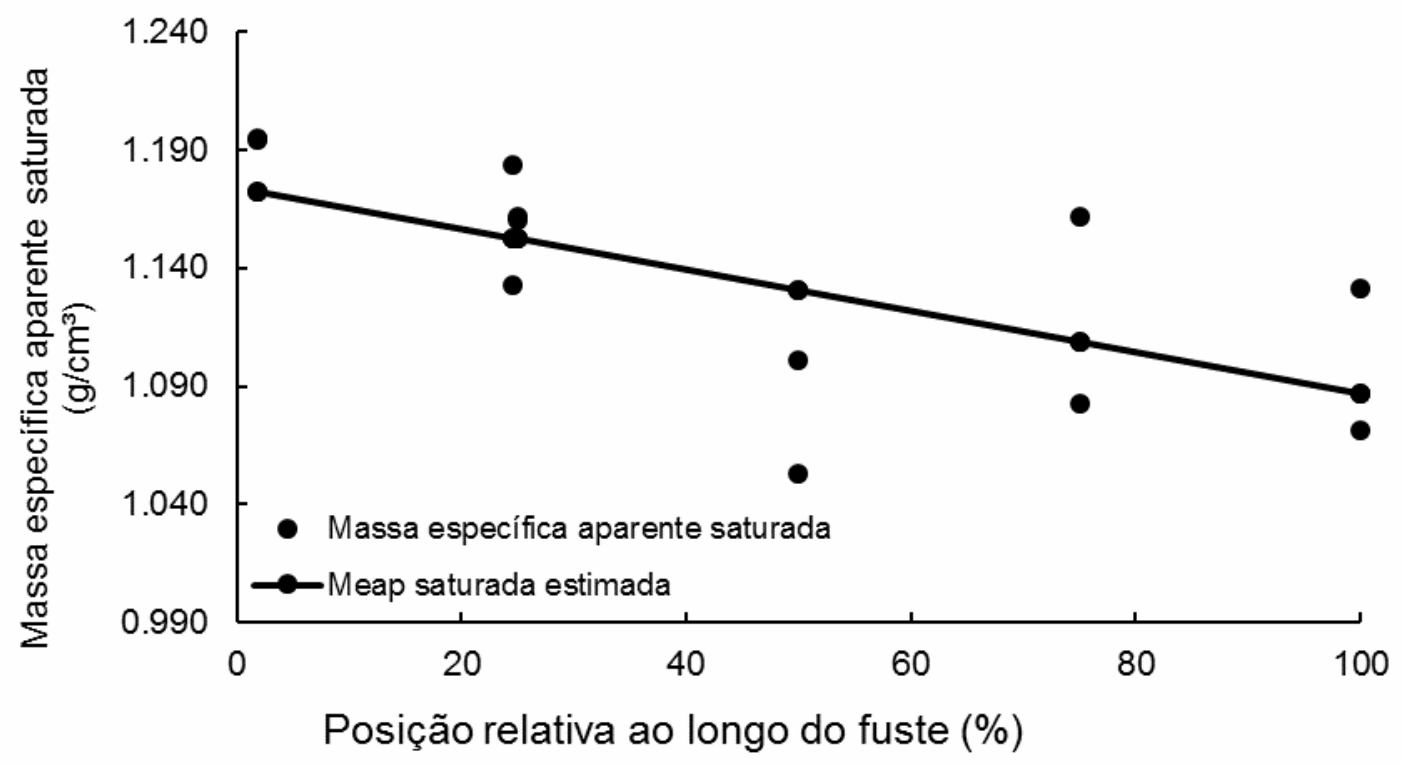

FIGURA 3 - Relação da massa específica aparente e a posição relativa à altura comercial ao longo do fuste.

\section{CONCLUSÕES}

A massa específica básica da madeira de Maclura tinctoria diminui com o aumento do teor de umidade e a massa específica aparente saturada apresenta uma tendência de acréscimo, porém sem diferença estatística.

A massa específica básica e a aparente saturada são menores próximo ao topo da árvore, enquanto o teor de umidade se mostra ligeiramente maior no sentido base-topo. De acordo com a massa específica básica ponderada em função do volume comercial sem casca a madeira dessa espécie pode ser classificada como média.

\section{REFERÊNCIAS}

AMERICAN SOCIETY FOR TESTING AND MATERIALS. ASTM D 143-94: Standard test methods for small clear specimens of timber. Philadelphia, 1995.

BELTRAME, R.; PERES, M. L. de; DELUCIS, R. de A.; FREITAS, D. L. de; GATTO, D. A. et al. Tensões de crescimento longitudinais e propriedades mecânicas da 
madeira de clones de Eucalyptus spp. Revista Matéria, Rio de Janeiro, v. 20, n. 4, p. 1061-1074, 2015. Disponível em: <http://www.scielo.br/pdf/rmat/v20n4/1517-7076rmat-20-04-01061.pdf>. doi: 10.1590/S1517-707620150004.0108.

BONDUELLE, G. M.; IWAKIRI, S.; TRIANOSKI, R.; PRATA, J. G.; ROCHA, V. Y. da. Análise da massa específica e da retratibilidade da madeira de Tectona grandis nos sentidos axial e radial do tronco. Revista Floresta, Curitiba, v. 45, n. 4, p. 971-680, 2015. Disponível em: <https://revistas.ufpr.br/floresta/article/view/31991/26918>. doi: 10.5380/rf.v45i4.31991.

CARVALHO, P. E. R. Ecologia, silvicultura e usos da Uva-do-Japão (Hovenia dulcis Thunberg). Colombo: EMBRAPA-CNPF, 1994, 24 p., (EMBRAPA-CNPF, Circular técnica, 23).

CARVALHO, P. E. R. Espécies Arbóreas Brasileiras. Embrapa Florestas, Curitiba, 2003.

CEZARO, J. A. de; TREVISAN, R.; BALBINOT, R. Propriedades físico-mecânicas da madeira de Chrysophyllum marginatum. Pesquisa Florestal Brasileira, Colombo, v. 36 , n. $86, \quad$ p. 135-143, 2016. Disponível em: <https://pfb.cnpf.embrapa.br/pfb/index.php/pfb/article/view/884/484>. doi: 10.4336/2016.pfb.36.86.884.

COLDEBELLA, R.; GIESBRECHT, B. M.; SACCOL, A. F. de O.; GENTIL, M.; PEDRAZZI, C. Propriedades físicas e químicas da madeira de Maclura tinctoria (L.) D. Don ex Steud. Ciência da Madeira, Pelotas, v. 9, n. 1, p. 54-61, 2018. Disponível em: <https://periodicos.ufpel.edu.br/ojs2/index.php/cienciadamadeira/article/view/10818/8 132>. doi: 10.12953/2177-6830/rcm.v9n1p54-61

CRISÓSTEMO, M. C.; GOUVEIA, F. N.; COSTA, A. F. da. Relação entre o teor de umidade e a constante dielétrica de espécies de madeira da Amazônia durante o processo de secagem. Revista Árvore, Viçosa, v. 40, n. 1, p. 181-187, 2016. Disponível em: <http://www.redalyc.org/pdf/488/48844658020.pdf>. doi: 10.1590/0100-67622016000100020.

DIAS, D. da C.; COLODETTE, J. L.; THIERSCH, C. R.; LEITE, H. G.; GOMIDE, J. L. Uso da técnica de resistografia e de variáveis dendrometricas na modelagem da densidade básica de povoamentos clonais de Eucalyptus. Ciência Florestal, Santa Maria, v. 27, n. 2, p. 609-619, 2017. Disponível em: <http://www.scielo.br/pdf/cflo/v27n2/1980-5098-cflo-27-02-00609.pdf>.

FRIEDERICHS, G.; BRAND, M. A.; CARVALHO, A. F. de.; KÜSTER, L. C. Qualidade da madeira e do carvão vegetal de bracatinga (Mimosa scabrella Benth.). Ciência da Madeira, Pelotas, v. 6, n. 2, p. 79-87, 2015. Disponível em: $<$ https://periodicos.ufpel.edu.br/ojs2/index.php/cienciadamadeira/article/view/4132/42 67>. doi: 10.12953/2177-6830/rcm.v6n2p79-8.

FUENTES-RAMíREZ, A.; PAUCHARD, A.; CAVIERES, L. A.; GARCÍA, R. A. Survival and growth of Acacia dealbata vs. native trees across an invasion front in ENCICLOPÉDIA BIOSFERA, Centro Científico Conhecer - Goiânia, v. 15 n.28; p.852 2018 
south-central Chile. Forest Ecology and Management, Amsterdã, v. 261, n. 6, p. 1003-1009, 2011. Disponível em: <http://www.lib.udec.cl/archivos_descargas_pdf/pdf_publicaciones_2011/FuentesRamirez_et_al_2011.pdf> doi: $10.1016 /$ j.foreco.2010.12.018.

GALINDO, E. A.; ALVES, E. U.; SILVA, K. B.; BARROZO, L. M.; MOURA, S. S. S. Germinação e vigor de sementes de Crataeva tapia L. em diferentes temperaturas e regimes de luz. Revista Ciência Agronômica, v. 43, n. 1, p. 138-145, 2012. Disponível em: <http://www.scielo.br/pdf/rca/v43n1/17.pdf>.

JUIZO, C. G. F.; LOIOLA, P. L.; ZEN, L. R.; MARCHESAN, R.; CARVALHO, D. E. et al. Variação radial das propriedades físicas da madeira de Pinus patula plantados em Moçambique. Pesquisa Florestal Brasileira, Colombo, v. 35, n. 83, p. 285-292, 2015. Disponível em: $<$ https://pfb.cnpf.embrapa.br/pfb/index.php/pfb/article/view/771>. doi: 10.4336/2015.pfb.35.83.771.

LOPES, G. A.; GARCIA, J. N. Densidade básica e umidade natural da madeira de Eucalyptus saligna Smith, de Itatinga, associadas aos padrões de casca apresentados pela população. Scientia Forestalis, Piracicaba, n. 62, p. 13-23, 2002. Disponível em: <http://www.ipef.br/publicacoes/scientia/nr62/cap01.pdf>.

MATTOS, B. D.; GATTO, D. A.; STANGERLIN, D. M.; CALEGARI, L.; MELO, R. R.; SANTINI, E. J. Variação axial da densidade básica da madeira de três espécies de gimnospermas Revista Brasileira de Ciências Agrárias, v. 6, n. 1, p. 121-126, 2011. Disponível em: <http://www.redalyc.org/pdf/1190/119018527018.pdf> doi: 10.5039/agraria.v6i1a1080.

OLVEIRA, J. T. da S.; HELLMEISTER, J. C.; TOMAZELLO FILHO, M. Variação do teor de umidade e da densidade básica na madeira de sete espécies de eucalipto. Revista Árvore, Viçosa, v. 29, n. 1, p. 115-127, 2005. Disponível em: <http://repositorio.ufes.br/bitstream/10/607/1/24241.pdf>.

PEREIRA, B. L. C.; OLIVEIRA, A. C.; CARVALHO, A. M. M. L.; CARNEIRO, A. C. O.; VITAL, B. R.; SANTOS, L. C. Correlações entre a relação Cerne/Alburno da madeira de eucalipto, rendimento e propriedades do carvão vegetal. Scientia Forestalis, Piracicaba, v. 41, n. 98, p. 217-225, 2013. Disponível em: < http://www.ipef.br/publicacoes/scientia/nr98/cap07.pdf>.

SKAAR, C. Wood-Water Relations. Springer-Verlag, Berlin, 1988. Disponível em: $<$ https://archive.org/details/woodwaterrelatio00skaa_0>.

TRAUTENMÜLLER, J. W.; BALBINOT, R.; BORELLA, J.; TREVISAN, R.; BALESTRIN, D. et al. Variação longitudinal da massa específica básica da madeira de Cordia americana e Alchornea triplinervia. Ciência Rural, Santa Maria, v. 44, n. 5, p. $\quad 817-821, \quad 2014 . \quad$ Disponível em: $<$ http://www.redalyc.org/html/331/33130634009/>. 
TREVISAN, R.; ZANELLA, A.; SILVA, F. M.; ROSA, M.; FIORESI, T; FORTES, F. O. Axial variation of basic density of Araucaria angustifolia wood in different diameter classes. Ciência Rural: Santa Maria, v. 46, n. 11, p. 1969-1972, 2016. Disponível em: <http://www.scielo.br/pdf/cr/v46n11/1678-4596-cr-0103_8478cr20141312.pdf> doi: http://dx.doi.org/10.1590/0103-8478cr20141312. 